\title{
Space Design in Batur Sari Villa in Sanur, Bali
}

\author{
Ida Bagus Gede Kresnayana Putra ${ }^{1}$, I Wayan Wiryawan ${ }^{2}$ \\ Bachelor Degree of Architecture Study Program \\ Faculty of Engineering-Udayana University \\ Jimbaran \\ kresnayanap@gmail.com \\ Architecture Study Program \\ Faculty of Engineering-Udayana University \\ Jimbaran
}

\begin{abstract}
Villa is a temporary place, which is located in a distant from crowded area in general villas are built in a place with not many residents and surrounded by beautiful nature to give comfort and serenity. One of the demands is how to maximiz-ing environmental atmosphere into design. Batur Sari villa is located in Sanur, which is identic with the coast. The de-mands is how to create the beach atmosphere in a villa and put into a design. An interior design with nautical concept could be a solution. The aims of interior design is for the development the function and psychological space and with this concept it can gives an environmental atmosphere inside the villa. Nautical concept identic with holyday feels in the beach. Sunshine, waves and sands could become inspirations, with the application of the concept inside the villa, a villa design could fulfill the needs of relax and serenity atmosphere with sorroundings characteristics that's is needed.
\end{abstract}

\section{Index Terms - villa, interior design, nautical concept}

\section{INTRODUCTION}

Sanur is one of the best tourist destinations in Bali, located on the coast. In this area there are many facilities for recreation, leisure and resting facilities, such as hotels, resorts, guesthouses and villas. The villa is a temporary residence located in an area that has a special landscape, for example the beach. As time goes by, Sanur has experienced many developments now without leaving the elements of nature and the environment they have. Therefore, to maintain the characteristics of the environment, the nautical concept was applied to the design of the space in Villa Batur Sari.

The design of the interior space is a technical solution into the building, this solution is functional to improve the quality of life, the culture of the occupants, and present an aesthetic impression, and create the principles of environmental preservation. The design of space in having three main things as a study, namely space, tools and humans. Balance, rhythm, scale, proportion, detail, unity, focal point and color. In the design of space there are seven processes in the application of the specified concepts, the first object observation is observing and exploring existing objects. Second, determining the concept of determining the rationale for solving design problems. Third, the preliminary sketch is a sketch of the application of the concept into the design. Fourth, the arrangement of furniture is the application of the concept of furniture used. Fifth, the material setting is the application of the concept to the materials of each element, Sixth, the lighting setting is the application of lighting to strengthen the concept, and 
finally the setting of the artwork is the addition of finishing in the form of artwork related to the selected concept.

The nautical concept is one of the concepts in the design of the interior which is synonymous with relaxing holidays on the beach, decorative elements inspired by sunlight, waves and sand. Characteristics of the nautical concept are, abundant sunlight, clean and light material when exhaled by the wind, white as a base combined with blue from the brightest to the darkest, natural fibers in informal furniture materials with shades of pan.

\section{RESUlt AND ANALISYS}

\section{A. Application of the Nautical Concept in the Space}

Space in is one of the most important parts of the building, to create the needs of the coastal atmosphere various nautical concept characteristics are applied to the design[1]. The main purpose of the application of the nautical concept is to create the impression of a beach with a relaxed and calm atmosphere. The nautical concept is applied to every element of inner space.

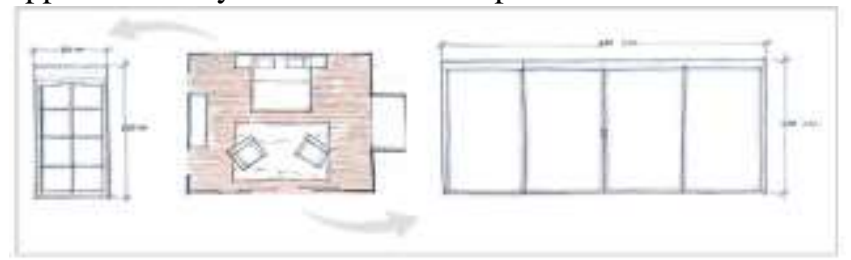

Fig. 1. Silculation

Figure 1 Characteristics of abundant sunlight, applied with the number of openings with a dimension that is wide enough so that sunlight can enter properly. Openings used in the form of sliding doors with dimensions of $400 \mathrm{~m} \mathrm{x}$ $200 \mathrm{~m}$ and windows with dimensions of $200 \mathrm{~m} \times 80 \mathrm{~m}$ as access to incoming light will strengthen the atmosphere of the coast. The application of sufficiently wide dimensions is the best solution.

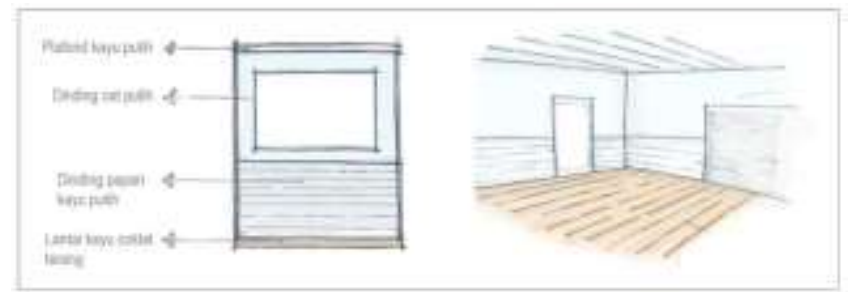

Fig. 2. Window

Figure 2 is the application of pale neutral and natural fiber to the interior space elements, and the application of white as the main color. White wrna is used as the basis of all colors chosen, because of the neutral nature it has. White combined with blue, starting from the lightest to the darkest. Materials with natural fibers are applied to each element, i.e. the elements of the white wooden ceiling, side elements of white paint walls and white wooden plank walls, and elements under the floor of light brown wood.

\section{B. Furniture Setting}

Furniture is a tool to support civitas activities. To strengthen characteristik nautical concept, arranged furniture which can create a calm and atmosphere relaxing in space while still maintaining hold the shades of the beach. Application of concepts nautical on furniture done with use of natural materials and applications nautical color characteristics in furniture. bed which is dominated by white and blue as shades of the beach. The sofa is placed with an orientation to the door equipped with blue pillows with nautical characteristics. Display shelves, nightstand, and tables use natural wood material with white finishing to strengthen the natural impression.

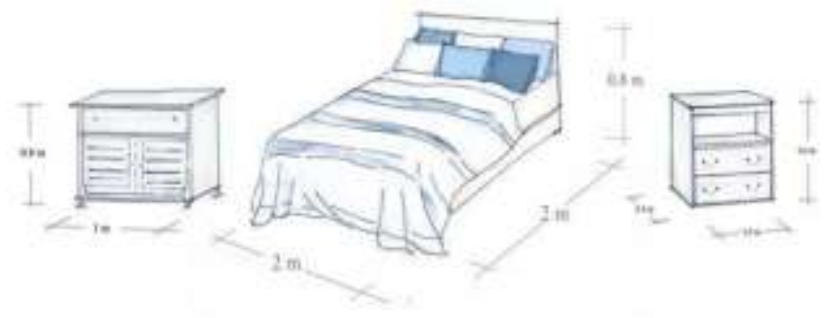

Fig. 3. Furniture Scale

\section{Material Setting}

Finishing material is characteristic of the concept of an interior space plan. In the nautical concept the material characteristic used is the use of natural fibers. Clean and lightweight material when blown by the wind, and white as a base combined with blue which gives a coastal feel to the design.

Figure 4 is the application of the nautical concept to the material-material making up the space element. On the ceiling and the bottom wall used wood with white doff Dulux V-Gloss paint finishing, used to give the impression of clean and natural. Side elements using Dulux Pentalite Moon Shimmer color finishing paint, applied to give the impression of clean and spacious so as to create a calm and relaxed atmosphere. El-emen used Kendo Canadian Maple's wooden floor to give a natural impression and used brown with sand as the main design inspiration.

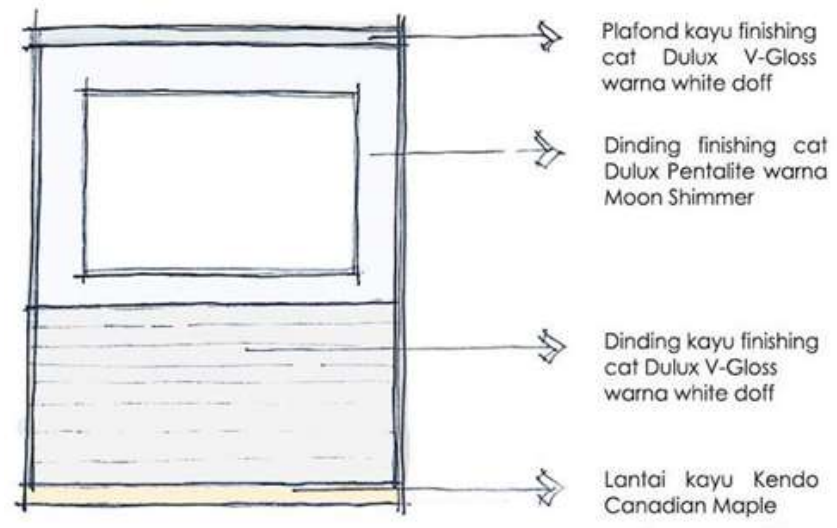

Fig. 4. Materials Setting

\section{Lighting Setting}

In planning space in lighting is one of the most important factors. Lighting is not only functional but also 
has aesthetic value. There are two types of lighting, namely general lightning which is lighting that must be evenly distributed in the room, serves to support activities, and decorative lightning which is lighting that plays a role for the beauty of space. In the nautical concept lighting arrangement is identical to the feel of the sea. The use of white and yellow light dominates in space.

Figure 5 is the arrangement of lighting in a room in a villa with a nautical concept. There are several types of lighting that are used, to create the impression of a coastal lamp shade used with a model of lighting on the ship as its characteristics. Wall lamp is placed in the dressing area and bookshelves, direct lighting type with white light. LED lights are used as the main lighting placed in the middle with white light. Down-light is used in every corner of the room, the yellow light gives an intimate impression. Table lamp in the bedroom, indirect lightning type placed next to the bed.

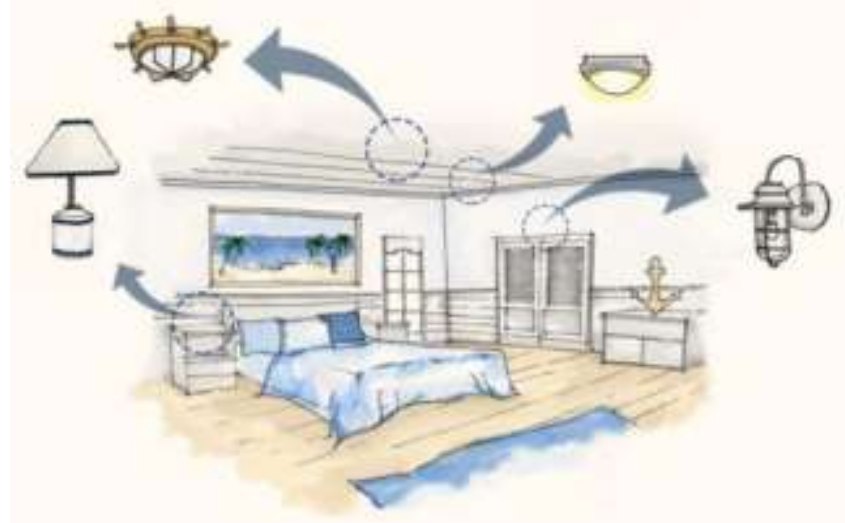

Fig. 5. Lighting Setting

\section{E. Artwork Setting}

In space planning the artwork has many functions. A room cannot be separated from the existence of artwork as an aesthetic enhancer. Besides the main function to beautify the room, artwork can provoke creativity and imagination and create a different atmosphere in the room. To reinforce the nautical concept that is applied to space, several artworks are used that characterize the coast. The artwork used is dominated by blue and white designs, inspiring sea, beach and sailing ships.

Figure 6 is the artwork used in the design. Pan-tai as the main inspiration for the arrangement of artwork. Beach painting with white frames on the main wall. DIY wall decoration is placed in small corners of space. Cushions on the sofa with a coastal design, a display rack with various bottle displays and shells. Ship steering wheel decoration on the wall gives the atmosphere of the sea. Wooden wall clock in pale blue gives a natural impression. With finishing the room artwork becomes increasingly impressed with life and the impression of the coast that you want to display can be clearly felt.

Figure 7 is a spatial atmosphere that has been arranged with the nauti-cal concept. After the arrangement of furniture with natural materials with shades of the beach; finishing material with a white base color; lighting that is identical to the atmosphere of the sea; and artwork with the beach as design inspiration, the impression of the coast in space can be felt clearly. The atmosphere is calm and relaxed which makes the room inside seem to blend with the atmosphere of the beach.

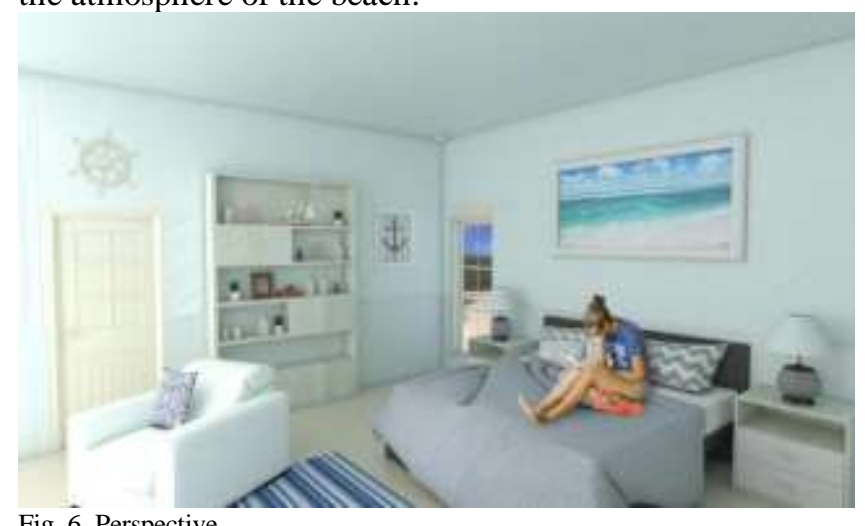

Fig. 6 . Perspective

\section{CONCLUSION}

Villa as a temporary residence, generally used for a place to stay when on vacation is required to be able to provide a calm atmosphere to the civitas in it. To create an atmosphere of calm and harmony with the surrounding environment, the design of a deep space can be a solution. The nau-tical concept in the interior is the most appropriate arrangement to create a beach atmosphere in a villa located around a coastal area. With the application of the nautical concept to the interior space, it can create the impression of calm, relax, and clean which is characteristic of the beach, thus the design of the space in the villa can be harmonious with the atmosphere of the surrounding environment. In structuring the nautical concept of deep space, there are several things that must be considered, namely the arrangement of furniture with natural materials with shades of the beach; finishing material with a white base color combined with blue and brown; lighting that is identical to the atmosphere of the sea; and artwork inspired by the state of the sea.

\section{REFERENCES}

[1] Jecks, Charles., "The New Pradigm in Architecture", London : Yale University Press, 2002. 